\title{
Reply to the comments on our article "Comparison of various surgical methods in the treatment of implant-related infection"
}

\author{
Muhittin Șener • Cemal Kazimoglu
}

Received: 31 July 2009 /Published online: 19 August 2009

(C) Springer-Verlag 2009

We are pleased to read the fruitful comments on our article and would like to explain some important issues raised by Cai et al. [1,2].

First of all, in our opinion the statistical tests used in the study (Mann-Whitney U test) are appropriate for such a study and there seems no need for other analyses. Additionally, we also stated in the discussion section of the text that the main weakness of the study was the small number of animals.

We are also surprised to read the authors interpretations of our study methodology. The aim of our study was to address solutions for deep infection developed soon after intramedullary fixation of long bone fractures; therefore, the setting of the study was not a chronic osteomyelitis model. We agree with the statement that lengthening the impregnation time would facilitate the antibiotic impregnation into bone and prolong the $T>$ MIC. However, we tried to put forward clinically applicable solutions for early postoperative deep infection. One hour is an acceptable period for antibiotic impregnation allowing the procedure to be done during surgery. Studies in the related literature have shown that one hour antibiotic impregnation provides effective antibiotic impregnation to bone [3, 4]. Our model was the establishment of early deep implant related infection; thus, it is not prerequisite to remove a stable implant which would inevitably increase the morbidity in clinical applications. It is a well known fact that restoring the bony continuity takes priority over treatment of the infection in clinical situations.

Some details concerning the fabrication of teicoplaninloaded bone grafts and acrylic beads such as surface area and bulk volume may also affect the antimicrobial efficacy. We are in agreement with the pertinent interpretations.

Finally, we disagree with the writers' conclusions. Even though the use of antibiotic-loaded cement beads has associated complications, it should be the treatment of choice for resistant infections because of its effectiveness when the infection cannot be controlled with debridement and antibiotic treatment.

\section{References}

1. Şener M, Kazimoglu C, Karapınar H et al (2009) Comparison of various surgical methods in the treatment of implant-related infection. Int Orthop. doi:10.1007/s00264-009-0750-0

2. Cai XZ, Jin AD, Yan SG (2009) Did local teicoplanin delivery systems inhibit or aggravate implant-related infection? Int Orthop. doi:10.1007/s00264-009-0830-1

3. Witsø E, Persen L, Benum P, Aamodt A, Husby OS, Bergh K (2004) High local concentrations without systemic adverse effects after impaction of netilmicin-impregnated bone. Acta Orthop Scand 75(3):339-346

4. Witso E, Persen L, Benum P, Bergh K (2005) Cortical allograft as a vehicle for antibiotic delivery. Acta Orthop 76:481-486

M. Șener $(\varangle) \cdot$ C. Kazimoglu

Department of Orthopaedics and Traumatology,

Ataturk Training and Research Hospital,

Izmir, Turkey

e-mail: msener87@yahoo.com 